\title{
Teacher Decision-Making: Using Hypothetical Vignettes to Examine the Course Recommendation Process
}

\author{
Philip E. Bernhardt \\ Metropolitan State University of Denver
}

\begin{abstract}
Academic tracking is common in American schools. While the impact of this practice on students is well documented, few studies closely examine the influence of teacher decisionmaking on students' academic trajectories. This article discusses a study examining how teachers recommend students for high- and low-track academic classes. Specific attention is paid to data collected through participant analysis of hypothetical vignettes. This unique methodology was specifically designed to illuminate the dynamics shaping participants' decision-making process. The key finding of this study is that participants experienced high levels of autonomy when making recommendations. This autonomy, however, did not emanate from recognition of their expertise or familiarity with students' academic capabilities; rather, it resulted from ill-defined expectations, poor communication among teachers, and a lack of clear administrative policies. The analysis of data led to findings that are divided into five distinct but interrelated themes.
\end{abstract}

Keywords: course placement, academic tracking, teacher decision-making, hypothetical vignettes

\section{Introduction}

Academic tracking is still a common dynamic in American secondary schools. Although the outcomes and consequences of this deeply entrenched practice are well documented, the influence of teacher decision-making on students' academic pathways is underresearched (see Darling-Hammond, 2010; Gamoran \& Berends, 1987; Giersch, 2016; Hallam \& Ireson, 2001; Kalogrides \& Loeb, 2013; Kelly, 2007; Oakes, 2005; Oakes \& Guiton, 1995; Oakes, Gamoran, \& Page, 1992; Steenbergen-Hu, Makel, \& Olszewski-Kubilius, 2016; Watanabe, 2006) More specifically, there is a lack of research investigating the role of teachers in making decisions about students' academic placement and the various dynamics shaping and informing these decisions. To increase access and opportunities for students to participate in the international baccalaureate program, advanced placement course, and other honors or advanced-level classes, it is essential to more deeply understand these issues.

The focus of this article is to highlight findings from a case study examining how three teachers working in one high school understand the course placement process and recommend academic placement of their students. Data collected through participant analysis of hypothetical student vignettes was a central focus. After considering vignettes, participants were asked to provide perspectives about those student characteristics most significant when making course placement recommendations, why these characteristics were important, and whether they would recommend students for a low-track or high-track class. This specific method of data collection was purposely selected because it provided an ideal context for surfacing the nuances, commonalities, divergences, and complexities shaping how teachers make important decisions within a school context. 


\section{Why Investigate Course Placement?}

Examining the course placement process is significant for a number of reasons. First, there is a connection between course enrollment in the years surrounding a student's transition from middle into high school as well as future course taking (Darling-Hammond, 1995; Kanno \& Kangas, 2014; Lucas, 1999; Mickelson \& Everett, 2008; Royster, Gross, \& Hochbein, 2015; Oakes, 2005). Kelly (2008) found students enrolled in low-track classes in early high school grades tend to still be enrolled in low-track classes at the end of high school, and academic mobility, once they were on a particular academic pathway, was often limited. Hence, a teacher's involvement with and influence on the course selection and placement process is an important area of inquiry that is frequently overlooked. Examining teacher participation can illuminate practices maintaining consequential academic patterns and provide deeper understanding about the academic courses students pursue (or do not pursue) and in which they ultimately enroll.

Second, participation in a rigorous academic curriculum is one relevant indicator of college readiness and enrollment (Adelman, 1999, 2006; Attewell \& Domina, 2008; Choy, Horn, Nuñez, \& Chen, 2000; King, 1996; Royster et al., 2015). The relationship between rigorous academic preparation and postsecondary education holds even more significance when considered within the context of researchers documenting low-income and minority students' traditional underrepresentation in both 4-year colleges (Baum, Ma, \& Payea, 2013; Berg, 2016; Cahalan \& Perna, 2015; U.S. Department of Education, National Center for Education Statistics, 2010) and high-track classes considered part of a college preparation course of study (Kelly, 2008; Oakes, 2005). Because of the relationship that exists between high school course taking and matriculation into higher education, more must be understood about how students are placed onto academic pathways preparing them for college.

Third, it can be argued that the policies and practices supporting academic tracking have, over time, expanded the "opportunity gap" that exists in many secondary schools (Darling-Hammond, 2010). This gap, which Darling-Hammond described as "the accumulated differences in access to key educational resources-expert teachers, personalized attention, high-quality curriculum opportunities, good educational materials, and plentiful information resources-that support learning at home and school" (p. 28), is a well-documented and serious consequence of academic tracking. Learning more about how students are placed into those classes may reveal insights about how to reduce this gap.

Last, detracking strategies, which are aimed at expanding academic opportunities and academic choice for all students, are advocated by a wide variety of education leaders and researchers (see Anderson \& Oakes, 2014; Burris \& Garrity, 2008; Lucas, 1999; Oakes, 2005; Wheelock, 1993). As teachers, administrators, and even parents across the United States work to tackle a deep history of inequity, exclusion, and marginalization within public schools, systemic efforts are being made to dismantle academic segregation in favor of detracking and the establishment of inclusive open course enrollment policies. That said, much more needs to be understood about the impact of teacher decision-making on students' academic pathways and the role of teachers within the academic placement process, as well as how to bridge the disconnect that often exists between school and district policies designed to move detracking toward sustainable implementation and what actually happens in practice.

\section{Review of Relevant Literature}

\section{Teacher Decision-Making}

There is an extensive body of research that considers teacher decision-making an activity that can be characterized as complex, context specific, nonlinear, inconsistently applied, driven by 
hierarchy, and highly personal. Some of this research includes studies focusing on differences in expert and novice decision-making (Wolff, Jarodzka, \& Boshuizen, 2017; Wolff, van den Bogert, Jarodzka, \& Boshuizen, 2015, 2016; Westerman, 1992), the role of teachers in administrative and educational decision-making (Conley, 1991; Ingersoll, 2006; Lortie, 2002; Rice \& Schneider, 1994), and the impact of organizational policies and practices on decision-making (Conley, 1991; Ingersoll, 1994, 1996, 2006). This research on teacher decision-making tends to focus on the extent of teacher participation, the various instructional and managerial domains in which teachers are involved, how school climate and organizational structure impact decision-making, and the internal cognitive processes shaping and impacting decision-making. Academic tracking, however, is rarely addressed in any meaningful way within the teacher decision-making literature. This omission is significant because these decisions are integral to what Oakes (1992) referred to as the political dimension of tracking or the "public labels, status differences, expectations, and consequences for academic and occupational attainment" (p. 13). Additionally, although academic tracking literature captures school- and district-level dynamics perpetuating and upholding this common practice, the research overlooks the multifaceted and complicated relationship between teachers' decisions, student course placement, and academic tracking.

There are three dynamics that emerged from the teacher decision-making literature that are important to consider. First, decision-making cannot be easily mapped or predicted. Rather, decisionmaking is context-specific, can be interpreted in multiple ways, and requires examining the experiences of those teachers directly involved in the process of making academic recommendations for students. Additionally, conceptualizing teacher decision-making as a logical and linear process does not allow space for the complexity, messiness, and unpredictability that is common in many schools. Second, investigations of teacher decision-making that draw on "multiple scales of analysis" (Helfenbein, 2010, p. 304) allow for both local and global perspectives to surface and provide multiple opportunities for understanding. Hence, honoring a variety of perspectives and data sources is useful for understanding how decision-making unfolds in practice. Third, when investigating teacher decision-making, it is useful to adopt a research perspective that takes into account the partiality of knowledge and the multiple ways in which truth and reality are formed, transmitted, and represented (Helfenbein, 2010).

\section{Teachers' Beliefs}

Beliefs are useful indicators for examining individuals' decisions. Beliefs, it can be argued, shape our expectations, perceptions, perspectives, attitudes, values, judgments, and experiences and, ultimately, direct our actions. Teachers' beliefs influence their day-to-day educational practices, decisions, and commitments. Shedding light on the significance of teacher beliefs, George and Aronson (2003) wrote, "like all of us, educators bring their own cultural beliefs to their schools. It is through this lens of these beliefs that they assess students' abilities, judge their potential for achievement, and help decide their futures by opening doors or closing them" (p. 4). An informed understanding of teachers' beliefs not only provides opportunities for improved classroom practice (Borg, 2018; Buehl \& Beck, 2015; Feiman-Nemser \& Floden, 1986; Milner, Sondergeld, Demir, Johnson, \& Czerniak, 2012; Pajares, 1992), but as Renzaglia, Hutchins, and Lee (1997) attested, "there is evidence that teachers' beliefs and attitudes drive important decisions" (p. 361). For example, teachers who believe in a growth mindset are more likely to encourage their students to enroll in challenging classes even though they might struggle, and those prescribing to a more fixed understanding of academic ability and development may be more restrictive when recommending students for challenging academic opportunities. 
Conceptualizing how beliefs emerge within the practice of teaching, Nespor (1987) offered a useful framework for examining what underlies and drives teacher decision-making. Nespor identified a number of distinct but interrelated characteristics related to individual beliefs useful for this study: existential presumptions, alternativity, and episodic structures.

\section{Existential Presumptions}

First, existential presumptions are deeply personal, take into account teachers' beliefs about the realities individuals encounter on a daily basis, are rarely affected by persuasion, and are often shaped by meaningful experiences. Existential presumptions can include belief statements such as "Not everyone should have access to advanced-level classes," "Not everyone can learn," or "You are just either smart or dumb-intelligence is fixed." Oakes and Guiton (1995) found that teachers believed student ability, motivation, and aspirations were fixed once they got to high school and that certain groups of students were associated in many educators' minds with particular academic tracks and opportunities. Hence, existential presumptions are important to note when considering teacher decision-making and how these beliefs shape teachers' actions. For example, in the context of this study, if a teacher believes honors classes are only for those they perceive as high achievers, to what extent does this influence their decision-making? What types of decisions does a teacher make when they associate disengagement and boredom with laziness and ability? Does the belief that every student has potential and can achieve at high levels influence a teacher's course recommendation decisions? Answers to these hypothetical questions could certainly shed light on different approaches to decision-making.

\section{Alternativity}

A second characteristic concerns the existence of alternative realities that differ from one's current understandings or experiences (Nespor, 1987). In the context of tracking and how teachers make recommendation decisions, this perspective of alternativity could include considering what it might mean to critique or alter current academic placement practices, reflecting on how tracking limits and harms certain groups of students, by asking questions about the ways in which tracking pushes students toward differing academic paths or even brainstorming how to have meaningful dialogue with colleagues about academic tracking and the consequences of this well-entrenched practice. Students live up to the expectations schools and teachers set for them, and imagining and advocating for improved opportunities for children is necessary for creating more equitable academic spaces for all students (George \& Aronson, 2003; Oakes, 1992; Pringle, Lyons, \& Booker, 2010; Rodríguez, 2012).

\section{Episodic Experiences}

A third characteristic of beliefs is rooted in influential episodic experiences throughout one's personal or professional life that help to shape understandings and actions that are put into practice at a later time (Nespor, 1987). For example, these can include prior or current teaching assignments (Finley, 1984), interactions with particular demographics of students (Oakes, 2005), learned expectations for students (Good \& Brophy, 2008), or even personal experiences being academically tracked (Ansalone \& Biafora, 2004). Such episodic structures within teachers' personal or professional lives can influence their perspectives about academic tracking, their perceptions of academic ability and student potential, and how they ultimately make course recommendations and decisions.

\section{Research Design}

This research study used a comparative, qualitative multiple-case study (Merriam, 2009; Stake, 2005) to examine how three social studies teachers working in one high school understand the course placement process and recommend academic placement of their students. 
The following research questions guided the study:

Research Question 1: What decision-making process guides how teachers recommend academic placement of students?

Research Question 2: What meritocratic and nonmeritocratic criteria guide teachers' course recommendation decisions?

Data was collected through survey, interviews, document analysis, and participant analysis of hypothetical student vignettes. Although this research could be conducted using a variety of methodologies, case study is ideal because it emphasizes in-depth description and analysis, triangulation of data sources, and what Cronbach called "interpretation in context" (as cited in Merriam, 2009, p. 42). During the interview process, study participants were asked to consider hypothetical student vignettes (Low, 1988; Schoenberg \& Ravdal, 2000) and explain the process employed to recommend academic placement (see Appendix A). After providing adequate time to consider each vignette, participants were asked a series of questions related to their decision-making process (see Appendix B). As part of this protocol, participants were also asked to describe and explain their current understanding of their school and academic department's process and policies for recommending the academic placement of students. The subsequent discussion of findings, conclusions, and areas for further research address data specifically collected from participant analysis of three hypothetical student vignettes.

\section{Hypothetical Vignette Analysis}

Writing about using vignettes in attitudinal research, Schoenberg and Ravdal (2000) suggested this process involves developing short, descriptive depictions of a circumstance or issue to "elicit rich but focused responses" (p. 63). The use of vignettes provides unique opportunities to discuss actions and decision-making in a specific context, converse and clarify participants' responses about their decisions, and explore sensitive and controversial topics in a nonthreatening way. In their research on the applications of vignettes, Hughes and Huby (2002) argued vignettes are useful in investigating "difficult topics of inquiry as they can desensitize aspects of these for participants" ( $p$. 384). Because participants could potentially find the research topic difficult or controversial to talk about, vignettes allow participants opportunities to respond in the third person and distance themselves from their everyday situation.

In a study of the criteria used by secondary science and English teachers to make course placement recommendations, Low (1988) used hypothetical vignettes to explore teachers' decision-making processes and reported this methodological approach not only enhanced understandings of interview data, but that "the use of vignettes created more realistic situations and allowed for comparison of responses" (p. 6). However, hypothetical vignettes have methodological limitations, such as they do not portray actual situations and can never fully capture how teachers make recommendations. Additionally, even though these vignettes may be considered narrow in scope, having participants analyze vignettes helps illuminate the various cognitive and affective processes teachers use to make decisions and provides a descriptive context for conversation, and because the vignettes are fictional, participants are able to distance themselves from the students with whom they interact on a daily basis.

Drawing on both Low's (1988) study and literature on academic tracking, hypothetical student vignettes were developed using 10 characteristics: sex, race, socioeconomic status, course grades, percent of homework completed, attendance rate, extent of class participation, social behavior in relation to peers and teachers, participation in extracurricular activities, and future academic and/or professional goals. Low selected these characteristics because they have the potential to influence academic achievement, shape teacher perceptions of ability, provide insights about students' 
interests and personal background, and influence academic placement. Each vignette presented a hypothetical situation and provided an opportunity for participants to explain the process they would use to recommend academic placement.

Participants were asked to consider the same three vignettes; this consistency made it easier to compare and contrast responses and perspectives. Each vignette was read aloud, and then participants had an opportunity to read them individually. During both readings, participants were encouraged to record their thoughts and ideas. After providing adequate time to consider each vignette, teachers were asked a series of questions related to their decision-making process (see Appendix B). These questions provided not only rich sources of data, but also opportunities to ask relevant follow-up questions.

\section{Findings and Conclusions}

It became clear after analyzing data that there were no clearly articulated administrative policies or expectations for placing students into classes. As a result, participants made placement recommendations without clear guidance on how they were supposed to do it or which criteria they were supposed to use. Additionally, participants specific roles and responsibilities within the academic placement process were never made unclear, were not written anywhere, and as a result, were left to individual interpretation. Due to this lack of guidance, Ken, Kay, and Amy (pseudonyms), the study's three participants, acted autonomously when making course recommendations. This also included selecting what they perceived as relevant meritocratic and nonmeritocratic criteria to guide recommendation decisions. Meritocratic criteria traditionally refer to objective determinants of ability and intelligence like standardized test scores, grades, and prior course placement, while nonmeritocratic course placement criteria tend to rely more on characteristics such as race, ethnicity, and social class, academic potential, behavior, motivation, personal interests, attitude, and/or family background. Each study participant established academic benchmarks and behavioral dispositions they believed students needed to possess or demonstrate to be successful in advanced-level coursework. Additionally, participants' recommendation decisions were actually impacted by their own experiences being academically tracked when they were in high school. It is also important to note that there was no requirement or expectation to communicate with colleagues, counselors, students, or even parents prior to making final recommendation decisions. Each participant made recommendation decisions with complete autonomy. The analysis of data led to findings that are divided into five distinct, but interrelated, themes.

\section{Structural Looseness}

Although one participant did report that a number of recent recommendations to move students into advanced-level courses resulted in questions from the department chair, this type of oversight was an exception rather than the rule. Ken, Amy, and Kay found themselves with the autonomy to make course recommendations completely on their own terms. In fact, they even admitted they made recommendations without a clear understanding about what is required of students in higher level social studies courses. It is important to note, however, that the autonomy participants experienced did not result from recognition of their expertise or detailed knowledge of their students' academic capabilities; rather, it resulted from ill-defined expectations, a lack of established policy, and poor communication at both the school and department levels. All three participants reported the same experience - they did not know of any policies, they received no information or guidance about how to make decisions or what criteria to consider, and they did not speak with colleagues about how the process was to be put into practice.

Interpreting data from a number of his large-scale studies of teacher decision-making, Ingersoll (2006) concluded that even though schools can be considered large bureaucracies that often strip 
away individual autonomy, they are also, at the same time, decentralized institutions in which teachers have a high degree of control over decisions directly connected to and impacting their daily lives. This model of "structural looseness" suggests teachers have control over a number of key decisions within the school that are "subject to few rules and regulation, receive little administrative surveillance, and have lots of room for the exercise of personal discretion by teachers, especially within the confines of the classroom" (p. 34). Observing this same organizational pattern a number of years earlier, Lortie (2002) concluded, "Classrooms are small universes of control with the teacher in command" (p. 30). Considered together, these descriptions of teacher decision-making align with participants' explanations and experiences of how they recommend academic placement; they each perceived and acted with a high degree of control, made decisions without interference from others within the school or their academic department, and were not subject to direct oversight when making course recommendation decisions. This autonomy led to inconsistent decisions, favoritism toward certain students, and a recommendation process that differed among participants.

\section{Course Placement Criteria}

There were a number of commonalities among participants regarding the course recommendation criteria they used to make decisions. First, because participants could not draw on school- or department-level policies and were tasked to participate in an unguided process, all three participants relied on their experience and expertise to select what they perceived as relevant recommendation criteria. This autonomy definitely led to a more subjective selection of criteria. Second, all three participants reported that the selected criteria were chosen because they believed they were in the best interests of their students. Hence, the academic well-being of students was at the core of the teachers' decision-making process. Their decisions were rationalized through a lens that reflected a genuine sense of care and concern for students' academic well-being. Third, Ken, Kay, and Amy relied on a variety of different criteria when recommending academic placement. All three participants reported they used a variety of meritocratic measures to inform decisions. These included grades on writing assignments, understanding of content as demonstrated through tests scores, and consistency with completing homework assignments. Additionally, two of the participants, Ken and Kay, offered specific examples of nonmeritocratic criteria they like to consider. Both teachers stressed the importance of students' work ethic and motivation, level of participation, on-task behavior, and future potential. What is interesting to note is that although each participant provided a strong rationale for utilizing these criteria, neither offered much insight into how they are actually measured. Nonetheless, both participants stressed a need to consider nonmeritocratic criteria when recommending academic placement.

These findings are fairly consistent with those in some of the literature on academic placement. For example, both Kelly (2007) and Gamoran (1992) found that it was common for schools, academic departments, and even individual teachers within these departments to use divergent placement criteria. Oakes, Joseph, and Muir (2004) found the criteria used by educators to decide which courses were most appropriate for students were rarely uniform. Rather, they relied on "subjective judgments about students' personalities, behavior, and motivation" (p. 79). Cesario (2006) came to similar conclusions. Many schools, she argued, do not have established criteria for placing students into ability groups, and as a result, certain groups of students have difficulty accessing courses that address higher level concepts and knowledge. Considered together, both the findings and reviewed literature suggest that a lack of clearly defined criteria has the potential to lead to decision-making that is subjective, inconsistent, and ultimately not in the best interest of all children.

\section{Undefined Roles}

Although the autonomy Ken, Amy, and Kay experienced provided tremendous flexibility and a sense of power over the recommendation process, they also reported that this autonomy also had its 
disadvantages. To begin, the three participants clearly understood their responsibility to recommend students for subsequent social studies classes, but they were not clear as to how their roles as teachers aligned with other school-level practices related to placing students in classes. For example, they all reported that they were unaware of information such as how students learned about course options, to what extent students interacted with guidance counselors or their parents regarding course taking, and the extent to which teacher recommendations actually influenced students' final placements. In fact, all three participants admitted they were uncertain about what happened to recommendations once they left their hands. They also admitted that they never put much effort into finding out of whether their recommendations actually aligned in any way with a students' future enrollment. Even though all three participants believed it was important to know more about how their role and decisions fit or aligned with other people and processes within the school, they did not think it was their responsibility to seek out information, change the process, or provide input. Ultimately, the believed they were completing the tasks they were responsible for and doing their job.

\section{Lack of Collaboration in Decision-Making}

Participants were also clear that the course recommendation process was not addressed in any meaningful way during department meetings or professional development activities. As a result, participants made course recommendations independent from one another and their other colleagues; the process lacked any type of collaboration. This lack of collaboration had two primary consequences. First, Ken, Amy, and Kay were, for example, recommending students for the same 10th-grade courses, but they did not communicate with one another regarding the criteria influencing their decisions. Hence, there was no consistency among participants in how students were recommended for these classes.

Second, an information gap existed within the department between standard- and advanced-level teachers. For example, Ken, Amy, and Kay had not been involved in discussions with colleagues about the skills and abilities students to need to succeed in higher level classes or how to best prepare students to make the transition into more academically rigorous courses. Moreover, Kay and Amy admitted they were unaware of any curriculum or assessments used in honors and international baccalaureate classes. Although participants had autonomy to make recommendations without having to discuss criteria, students, or the process with their colleagues, this lack of communication made it difficult for participants to really understand the nuances of the coursework students were transitioning to, the expectations for these classes, and which criteria they should be using when making decisions. Participants had limited perspective of the various academic pathways within their own department and did not fully understand the curriculum, expectations, or academic demands of the classes for which they were recommending students.

\section{Perceptions of Impact}

Participants also expressed genuine concerns about whether they really had an influence in determining students' academic pathways. Specifically, they did not perceive that their recommendations were used in any practical way to influence the courses in which their students actually enrolled. Researching the decision-making domains in which teachers have an influence, Ingersoll (2006) detected similar perceptions; teachers, it was concluded, have little say over which "students were placed into which tracks or ability levels" (p. 77).

Data from this current study revealed that participants operated under the assumption that other individuals, namely students, parents, and guidance counselors, had a much larger and more direct impact on the course placement process. In addition to not knowing much about how students are placed in classes, the participants also never received information from counselors about the courses 
in which students actually enrolled. As a result, they did not perceive that their recommendations influenced students' ultimate course placement. Consequently, participants did not put much effort, planning, or preparation into their decision-making. Although there was consensus among all three participants regarding the extent to which their recommendations influenced students' course assignments, their perspectives may not be completely accurate, as they may actually have a larger influence than they think.

Investigating how the system of tracking functions within schools and with what effects, Rosenbaum (1976) concluded that parents are often at the mercy of difficult-to-navigate structures and school norms and, as a result, do not exert much influence on placements. In her landmark study on tracking, Oakes (1985) found that the "locus of control of track decisions" in the 25 middle and high schools in which she conducted research resided with counselors and teachers together and neither parents nor students had any role in the decisions (p. 57). Although Ken, Kay, and Amy did not interact with parents when making recommendations, they did each suggest that parents have an important role to play in determining students' course placement.

Although there is limited research specifically investigating student involvement in course placement, available evidence suggests it is highly unlikely for a school to allow students to have a high level of discretion in selecting courses (Kelly, 2008; Oakes \& Guiton, 1995; Rosenbaum, 1976). In fact, Kelly's (2007) examination of 92 high school curriculum guides did not reveal a single school in which students were free to register for any academic courses they desired. Although it was not malicious, Ken, Amy, and Kay seemed to underestimate the significance of their recommendation decisions and their role in the process.

All three participants experienced a high level of autonomy when making course recommendation decisions. However, this autonomy was a result of ill-defined policies, guidelines, and expectations, as well as poor communication at both the school and department levels. Participants also reported that because policies were not clearly communicated, they felt disconnected from the school's larger course placement system. Consequently, they did not perceive their recommendation decisions as having a direct influence on students' course placement. Although all three participants cared about their students and believed their decisions reflected a vested interest in their students' success, the lack of a consistent, well-articulated process; the selection and application of subjective and divergent criteria; and the lack of collaboration or use of data to inform decisions created a system with the potential to create department culture that limits access and opportunity for some students.

\section{Moving Forward: Recommendations for Further Research}

Because this study examined only three teachers at one school site, further research is necessary. Three recommendations are offered for future research. First, because the purpose of this study was to investigate the how teachers recommend academic placement of students, no attempt was made to collect data linking teachers' decisions to students' actual course enrollments. Additionally, even though the study was conducted in a high school serving a large population of low-income students (40-50\%), there was not an attempt to collect information about student demographics or whether they qualified for free and reduced lunch. Future research on this topic should take into account students' final placements and demographic characteristics as well as free and reduced lunch status. This information would not only illuminate the extent to which teachers influence course enrollment, but it would also provide needed insight about the relationship between teachers' course recommendations and research documenting the overwhelming presence of low-income and minority students in low-track classes.

A second recommendation is that research examining teachers' course recommendation practices needs to also include how decisions are being made in middle schools. It would be ideal to conduct 
research in a number of high schools and their feeder middle schools within the same school district. This large study would not only provide data identifying the various policies and processes used to place students starting in seventh grade, but it would also allow for a rich comparison of schools and teachers. The teachers participating in this study had little knowledge about the course placement practices at their feeder middle school. This line of inquiry deserves further consideration. Although tracking, particularly in social studies, is less prevalent in middle school, it is still important to understand how decisions are made about the courses students will take once they enter high school. Additionally, because middle schools tend to use grade-level team structures, it would be useful to investigate whether course placement practices in middle schools are more collaborative than in high school.

The final recommendation has to do specifically with research design. Although the methods used to collect data in this study provided valuable insights about how teachers recommend placement, these approaches did not provide opportunities for participants to interact with one another. Further research on this topic needs to incorporate collaborative inquiry groups so participants have the opportunity to construct meaning with one another. This interactive environment is important because it will enable teachers to listen to each other's perspectives and socially construct understanding, and will also provide a forum to discuss possible alternatives to inform and alter current recommendation practices.

Examining how tracking operates at the practitioner level in schools, Watanabe (2007) used yearlong inquiry groups to examine teachers' theories of ability and intelligence, current research, and the practice of tracking. In doing this, she was able to create a research environment in which teachers constructed new knowledge about the implications of tracking, identified ways in which their concerns about this practice overlapped, and engaged in meaningful discussions about research articles they selected. These types of inquiry groups can even serve as professional development, as they encourage teachers to engage with colleagues about issues impacting their work, discuss academic tracking, and potentially facilitate meaningful change within their school.

\section{References}

Adelman, C. (1999). Answers in the toll box: Academic intensity, attendance patterns, and bachelor's degree attainment. Washington, DC: U.S. Department of Education, Institute for Education Sciences.

Adelman, C. (2006). The toolbox revisited: Paths to degree completion from high school through college. Washington, DC: U.S. Department of Education.

Anderson, L., \& Oakes, J. (2014). The truth about tracking. In P. C. Gorski \& K. Zenkov (Eds.), The big lies of school reform: Finding better solutions for the future of public education (pp. 109128). New York, NY: Routledge.

Ansalone, G., \& Biafora, F. (2004). Elementary school teachers' perceptions and attitudes to the educational structure of tracking. Education, 125, 249-258.

Attewell, P., \& Domina, T. (2008). Raising the bar: Curricular intensity and academic performance. Educational Evaluation and Policy Analysis, 30, 51-71.

Baum, S., Ma, J., \& Payea, K. (2013). Education pays. Washington, DC: College Board.

Berg, G. A. (2016). Low-income students and the perpetuation of inequality: Higher education in America. New York, NY: Routledge.

Borg, S. (2018). Teachers' beliefs and classroom practices. London, United Kingdom: Routledge. 
Buehl, M. M., \& Beck, J. S. (2015). The relationship between teachers' beliefs and teachers' practices. In H. Fives \& M. G. Gill (Eds.), International handbook of research on teachers' beliefs (pp. 66-84). New York, NY: Routledge.

Burris, C. C., \& Garrity, D. T. (2008). Detracking for excellence and equity. Alexandria, VA: Association for Supervision and Curriculum Development.

Cahalan, M., \& Perna, L. W. (2015). Indicators of higher education equity in the United States. Washington, DC: The Pell Institute and Penn AHEAD.

Cesario, R.S. (2006). Reforming secondary math curriculum: A case study of teachers inspired, teachers entrenched (Doctoral dissertation). Center for Education, Widener University, Chester, PA.

Choy, S. P., Horn, L. J., Nuñez, A. M., \& Chen, X. (2000). Transition to college: What helps at-risk students and students whose parents did not attend college. In A. F. Cabrera \& S. M. La Nasa (Eds.), Understanding the college choice of disadvantaged students (pp. 45-63). San Francisco, CA: Jossey-Bass.

Conley, S. (1991). Review of research on teacher participation in school decision-making. In G. Grant (Ed.), Review of research in education (pp. 225-266). Washington, DC: AERA.

Darling-Hammond, L. (1995). Inequality and access to knowledge. In J. A. Banks (Ed.), The handbook of research in multicultural education (pp. 465-483). New York, NY: Macmillan.

Darling-Hammond, L. (2010). The flat world and education. New York, NY: Teachers College Press.

Feiman-Nemser, S., \& Floden, R. E. (1986). The cultures of teaching. In M. C. Wittrock (Ed.), Handbook of research on teaching (3rd ed., pp. 505-526). New York, NY: Macmillan.

Finley, M. K. (1984). Teachers and tracking in a comprehensive high school. Sociology of Education, $57,233-243$.

Gamoran, A. (1992). Access to excellence: Assignment to honors English classes in the transition from middle to high school. Educational Evaluation and Policy Analysis, 14, 185-204.

Gamoran, A., \& Berends, M. (1987). The effects of stratification in secondary schools: Synthesis of survey and ethnographic research. Review of Educational Research, 57, 415-435.

George, P., \& Aronson, R. (2003). How do educators' cultural belief systems affect underserved students' pursuit of postsecondary education? (Prepared for the Pathways to College Network). Honolulu, HI: Pacific Resources for Education and Learning.

Giersch, J. (2016). Academic tracking, high-stakes tests, and preparing students for college: How inequality persists within schools. Educational Policy. Advance online publication. doi: $10.1177 / 0895904816681526$

Good, T., \& Brophy, J. (2008). Looking in classrooms (10th ed.). New York, NY: Allyn \& Bacon.

Hallam, S., \& Ireson, J. (2001). Ability grouping in education. London: Sage.

Helfenbein, R. (2010). Thinking through scale: Critical Geography and curriculum spaces. In E. Malewski (Ed.) Curriculum studies handbook: The next moment (pp. 304-317). New York, NY: Routledge.

Hughes, R., \& Huby, M. (2002). The application of vignettes in social and nursing research. Journal of Advanced Nursing, 37, 382-386.

Ingersoll, R. (1994). Organizational control in secondary schools. Harvard Educational Review, 64, $150-172$.

Ingersoll, R. (1996). Teachers' decision-making power and school conflict. Sociology of Education, 69, $159-176$. 
Ingersoll, R. (2006). Who controls teachers'work? Cambridge, MA: Harvard University Press.

Kalogrides, D., \& Loeb, S. (2013). Different teachers, different peers the magnitude of student sorting within schools. Educational Researcher, 42, 304-316.

Kanno, Y., \& Kangas, S. E. (2014). "I'm not going to be, like, for the AP”: English language learners' limited access to advanced college-preparatory courses in high school. American Educational Research Journal, 51, 848-878.

Kelly, S. (2007). The contours of tracking in North Carolina. The High School Journal, 90, 15-31.

Kelly, S. (2008). Social class and tracking within schools. In L. Weis (Ed.), The way class works: Readings on school, family and the economy (pp. 210-224). New York, NY: Routledge.

King, J. (1996). The decision to go to college: Attitudes and experiences associated with college attendance among low-income students. New York, NY: College Board.

Lortie, D. (2002). Schoolteacher: A sociological study (2nd ed.). Chicago, IL: University of Chicago Press.

Low, D. (1988, April). Ability grouping: Decision-making at the secondary level. Paper presented at the annual meeting of the American Educational Research Association, New Orleans, LA. Retrieved from ERIC database. (ED297023)

Lucas, S. (1999). Tracking inequality: Stratification and mobility in American high schools. New York, NY: Teachers College Press.

Merriam, S.B. (2009). Qualitative research: A guide to design and implementation. San Francisco, CA: Jossey-Bass.

Mickelson, R., \& Everett, B. (2008). Neo-tracking in North Carolina: How high school courses of study reproduce race and class-based stratification. Teachers College Record, 110, 535-570.

Milner, A. R., Sondergeld, T. A., Demir, A., Johnson, C. C., \& Czerniak, C. M. (2012). Elementary teachers' beliefs about teaching science and classroom practice: An examination of pre/post NCLB testing in science. Journal of Science Teacher Education, 23, 111-132.

Nespor, J. (1987). The role of beliefs in the practice of teaching. Journal of Curriculum Studies, 19, $317-328$.

Oakes, J. (1992). Can tracking research inform practice? Educational Researcher, 21, 12-21.

Oakes, J. (2005). Keeping track: How schools structure inequality (2nd ed.). New Haven, CT: Yale University Press.

Oakes, J., Gamoran, A., \& Page, R. (1992). Curriculum differentiation: Opportunities, outcomes, and meanings. In P. Jackson (Ed.), Handbook of research on curriculum (pp. 570-608). New York, NY: MacMillan.

Oakes, J., \& Guiton, G. (1995). Matchmaking: The dynamics of high school tracking decisions. American Educational Research Journal, 32, 3-33.

Oakes, J., Joseph, R., \& Muir, K. (2004). Access and achievement in mathematics and science: Inequalities that endure and change. In J. A. Banks \& C. A. McGee Banks (Eds.), Handbook of research on multicultural education (pp. 69-90). San Francisco, CA: Jossey-Bass.

Pajares, M. F. (1992). Teachers' beliefs and educational research: Cleaning up a messy construct. Review of Educational Research, 62, 307-332.

Pringle, B. E., Lyons, J. E., \& Booker, K. C. (2010). Perceptions of teacher expectations by African American high school students. The Journal of Negro Education, 79, 33-40. 
Renzaglia, A., Hutchins, M., \& Lee, S. (1997). The impact of teacher education on the beliefs, attitudes, and dispositions of preservice special educators. Teacher Education and Special Education, 20, 360-377.

Rice, M. E., \& Schneider, G. T. (1994). A decade of teacher empowerment: An empirical analysis of teacher involvement in decision making, 1980-1991. Journal of Educational Administration, $32,43-58$.

Rodríguez, M. A. (2012). "But they just can't do it": Reconciling teacher expectations of Latino students. Journal of Cases in Educational Leadership, 15, 25-31.

Rosenbaum, J. (1976). Making inequality. New York, NY: Wiley \& Sons.

Royster, P., Gross, J., \& Hochbein, C. (2015). Timing is everything: Getting students back on track to college readiness in high school. The High School Journal, 98, 208-225.

Schoenberg, N. E., \& Ravdal, H. (2000). Using vignettes in awareness and attitudinal research. International Journal of Social Research Methodology, 3, 63-74.

Stake, R. (2005). Multiple case study analysis. New York, NY: Guilford Press.

Steenbergen-Hu, S., Makel, M. C., \& Olszewski-Kubilius, P. (2016). What one hundred years of research says about the effects of ability grouping and acceleration on K-12 students' academic achievement: Findings of two second-order meta-analyses. Review of Educational Research, 86, 849-899.

Watanabe, M. (2007). Lessons from a teacher inquiry group about tracking: Perceived student choice in course-taking and its implications for detracking reform. Teachers College Record, 109, $2136-2170$

Westerman, D. A. (1992). Expert and novice teacher decision making. Journal of Teacher Education, 42, 292-305.

Wheelock, A. (1993). Crossing the tracks: How “untracking” can save America's schools. New York, NY: New Press.

Wolff, C. E., Jarodzka, H., \& Boshuizen, H. P. (2017). See and tell: Differences between expert and novice teachers' interpretations of problematic classroom management events. Teaching and Teacher Education, 66, 295-308.

Wolff, C. E., Jarodzka, H., van den Bogert, N., \& Boshuizen, H. P. (2016). Teacher vision: Expert and novice teachers' perception of problematic classroom management scenes. Instructional Science, 44, 243-265.

Wolff, C. E., van den Bogert, N., Jarodzka, H., \& Boshuizen, H. P. (2015). Keeping an eye on learning: Differences between expert and novice teachers' representations of classroom management events. Journal of Teacher Education, 66, 68-85.

U.S. Department of Education, National Center for Education Statistics. (2010). The condition of education 2010 (NCES 2010-028). Retrieved from https://nces.ed.gov/pubs2010/2010028.pdf

[Appendices follow] 


\section{Appendix A}

\section{Hypothetical Student Vignettes}

1. Sarah, a White student who lives in one of the wealthiest neighborhoods in the school district, has an average of $80 \%$ in your class and turns in most of her homework assignments. She has four absences in the third quarter, but they are all excused. Sarah rarely asks questions or volunteers to answer questions. Overall, she tends to be disengaged and uninterested in class material, has a tendency to be disruptive during large group discussions, and clearly enjoys socializing with friends during class. Sarah has been late to class numerous times this year and has been removed from the classroom three times for being disruptive. A school guidance counselor recently noticed that many of Sarah's middle school teachers reported similar behavior patterns. At a parent-teacher conference early in the year, Sarah's parents inquired about the possibility of placing her in higher level courses. Sarah plays volleyball and sings in the chorus.

2. Luis, a middle-class Hispanic student, has an average of $75 \%$ in your class. During the second and third quarters, he has been absent 10 times due to an ongoing illness. When Luis returns after an absence, he seems overwhelmed and often has a difficult time making up missed assignments. As a result, only about half of his homework assignments are completed. However, his overall test average for the current school year is $80 \%$. Luis' counselor and a few of his teachers have recently learned that his parents are going through a stressful separation. Nonetheless, Luis participates in class, seems to really enjoy being in school and learning, and often discusses his interest in becoming a writer and following in his brother's footsteps at Tulane University. Additionally, Luis has expressed his enjoyment about studying history. Although Luis is a member of the Spanish club, it is difficult for him to participate in afterschool activities or school-provided tutoring services because he is responsible for babysitting his younger siblings.

3. Marcus, an African American student who qualifies for free and reduced lunch, has an $80 \%$ grade point average in your class. He has a number of absences this year (as of January) and besides a handful of tardies, tends to be on time to class. Marcus does not always complete his independent work (i.e., homework) on time and sometimes struggles in understanding content. Additionally, while he is not a great writer, Marcus seems to really enjoy the process and is really creative. He gets along well with classmates and has a collaborative disposition. While Marcus often asks for feedback on assignments before and after class, he does not consistently follow through with suggested improvements and does not schedule time to come in for help at lunch or after school. Even though he is extremely quiet during class, he pays attention, follows directions, and does seem genuinely interested in the subject matter. As a ninth-grader, Marcus plays a varsity sport and has also expressed an interest in possibly joining the band (he was in the band in middle school). He also has two older brothers who were in your class, but neither one of them pursued postsecondary education. Marcus has never specifically mentioned any career interests or plans to attend college, but he has mentioned an interest exploring advanced placement or international baccalaureate classes. 


\section{Appendix B}

\section{Hypothetical Vignette Analysis Protocol}

1. *Please describe and explain the process you currently use to recommend academic placement of students.

2. Please describe the student characteristics most important as you considered your decision.

3. Why were these characteristic important to you?

4. Would you recommend this student for a low-track or high-track class?

5. Is there any information missing from the vignette that you believe needs to be included when recommending academic placement? If so, please explain.

*Study participants are asked to respond to this question prior to reading hypothetical student vignettes.

The Journal of Educational Research and Practice provides a forum for studies and dialogue that allows readers to better develop social change in the field of education and learning. Journal content may focus on educational issues of all ages and in all settings. It also presents peer-reviewed commentaries, book reviews, interviews of prominent individuals, and additional content. The objectives: We publish research and related content that examines current relevant educational issues and processes aimed at presenting readers with knowledge and showing how that knowledge can be used to impact social change in educational or learning environments. Additional content provides an opportunity for scholarly and professional dialogue regarding that content's usefulness in expanding the body of scholarly knowledge and increasing readers' effectiveness as educators. The journal also focuses on facilitating the activities of both researcher-practitioners and practitioner-researchers, providing optimal opportunities for interdisciplinary and collaborative thought through blogging and other communications.

Walden University Publishing: http://www.publishing.waldenu.edu 